\title{
Una Especie Nueva de Zamia (Zamiaceae) de Honduras
}

\section{Cyril Hardy Nelson Sutherland ${ }^{1}$ y German Giovanny Sandoval González ${ }^{2}$}

Resumen. Se describe la especie nueva Zamia onan-reyesii del norte de Honduras.

Palabras clave: Gimnosperma, novedad.

Abstract. Zamia onan-reyesii is described as a new species from northern Honduras.

Key words: Gymnosperm, novelty.

\section{Introducción}

Desde 1950 se han descrito gimnospermas nuevas de la flora de Honduras; son ellas Dioon mejiae (Standley, 1950), Zamia standleyi (Schutzman 1989), Zamia oreillyi (Nelson Sutherland, 2005 [2007]) y Zamia sandovalii (Nelson Sutherland 2005 [2007]). También se ha encontrado una especie no descrita del género Ceratozamia en el departamento de Atlántida (Haynes y Bonta 2003). En el departamento de Cortés, en la montaña del Merendón, Honduras, se habían observado especimenes de una especie de Zamia, pero estériles, de la que finalmente se encontraron individuos fértiles y que se describen a continuación como una especie nueva.

Zamia onan-reyesii C. Nelson \& G. G. Sandoval, sp. nov. Figuras 1-6.

Frutex 2-metralis strobilo femineo $43 \mathrm{~cm} \times 11.6$ cm cylindrico, acuminato, pedunculo dense pubescenti.

Planta arbustiva hasta $2 \mathrm{~m}$ de altura; tallo aéreo de $1.92 \mathrm{~m}$ de altura, $14.3 \mathrm{~cm}$ de diámetro, anillado (Figura 1). Hojas (Figura 2) triangulares a romboides en número de 1-3 cuando la planta es joven, más de 15 cuando adulta, con una longitud de $1.81 \mathrm{~m}$ de largo por $0.47 \mathrm{~m}$ de ancho, pecíolo (Figura 2) de $40 \mathrm{~cm}$ de largo, glabro, con espinas cortas y filosas a lo largo de la base del pecíolo, el raquis glabro con espinas con hasta 29 pares de pinnas; raquis glabro con espinas (Figura
2); pinnas proximales al tallo de $19.5 \times 2.1 \mathrm{~cm}$, en el centro las pinnas miden $36 \times 3.9 \mathrm{~cm}$ y en el ápice de la fronda $13.4 \times 3.2 \mathrm{~cm}$, glabras, subcoriáceas subsésiles, falcadas, apicalmente acuminadas, los márgenes dentados con un promedio de 18 dientes por pinna (Figura 3). Cono femenino (Figuras 4-6) color verde $43 \mathrm{~cm} \times 11.6 \mathrm{~cm}$ de diámetro, cilíndrico, pedunculado, acuminado; pedúnculo densamente cubierto con pubescencia café $4.5 \mathrm{~cm} \times 20.6 \mathrm{~cm}$ de diámetro, acumen $4 \mathrm{~cm}$ de alto $\times 1.9 \mathrm{~cm}$ de ancho en el ápice, y $3.6 \mathrm{~cm}$ de ancho en la base; 9-12 escamas o macrosporofilas por cada columna por 6-7 escamas por fila, macrosporofila hexagonal de 4.7-1.7 cm de largo $\times 2.9-1.1 \mathrm{~cm}$ de ancho con pedicelo glabro $0.8-2.9 \mathrm{~cm}$ de longitud, color blanquecino hueso. Óvulos dos por macrosporofila, poligonales, blancos, glabros, cambiando de color al madurarse a color salmón, endospermo blanco. Estróbilo masculino no visto.

Holotipo. Honduras. Departamento de Cortés: montaña del Merendón, comunidad del Gallito, filo del Cerrito, $7 \mathrm{~km} \mathrm{~W}$ de San Pedro Sula, bosque húmedo

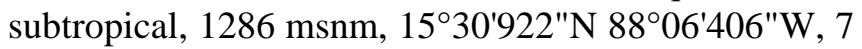
de enero de 2008, Onán Reyes 406 (TEFH).

Paratipo. Honduras. Departamento de Cortés: montaña del Merendón, filo del Cerrito, San Pedro Sula, bosque húmedo subtropical, $1090 \mathrm{~m}$, 15³1'012"N 8806'183"W, 31 julio 2003, Jody Haynes, Mark Bonta, German Sandoval, Carlos O'Reilly, Isidro Zúniga \& José Mendoza 45 (TEFH).

\footnotetext{
${ }^{1}$ Herbario Cyril Hardy Nelson Sutherland (TEFH), Departamento de Biología, Universidad Nacional Autónoma de Honduras, Tegucigalpa, Honduras,chnelsons@yahoo.com

${ }^{2}$ Herbario Cyril Hardy Nelson Sutherland (TEFH), sango54@hotmail.com
} 


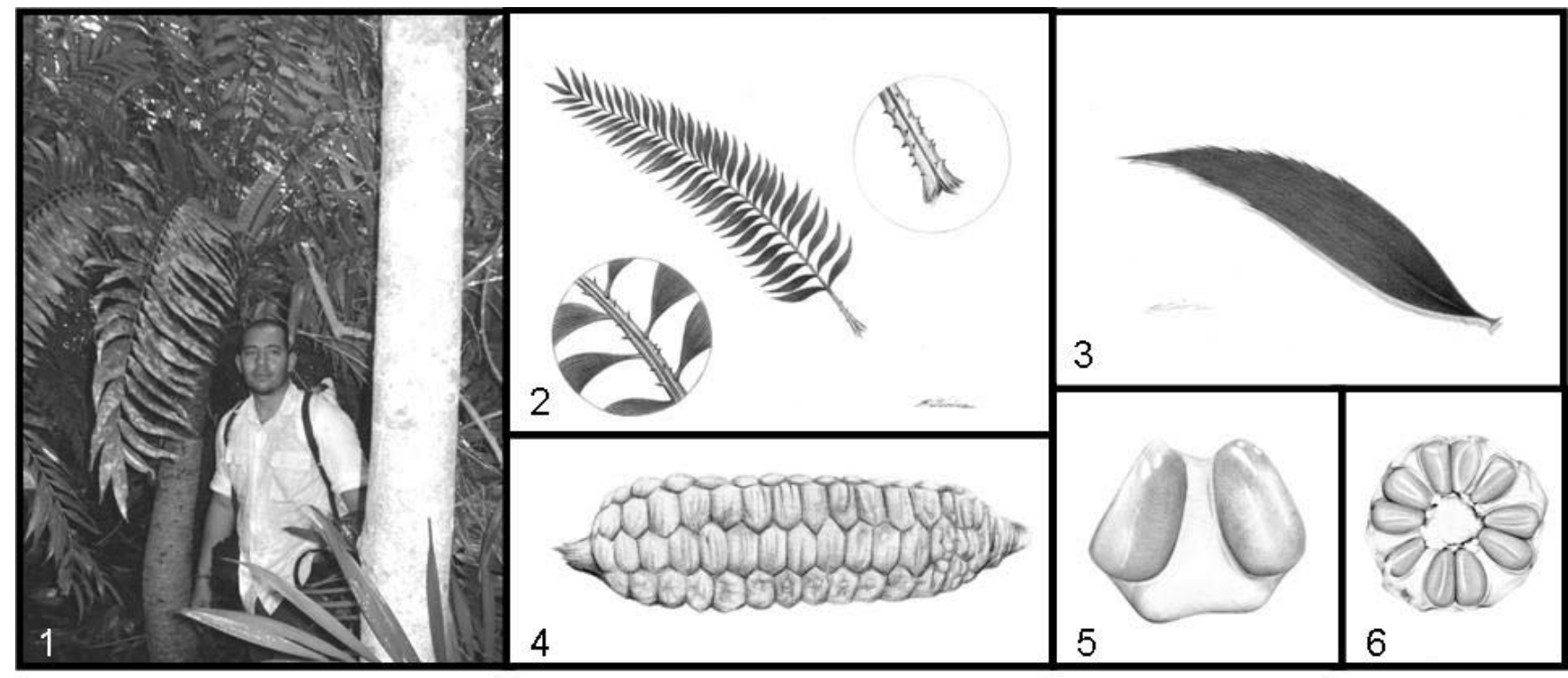

Figura 1. Onán Reyes junto a la planta tipo.

Figura 2. Zamia onan-reyesii. Hoja (al centro) eje de la hoja con bases de folíolos (izquierda) pecíolo (derecha). Figura 3. Zamia onan-reyesii. Folíolo.

Figura 4. Zamia onan-reyesii. Estróbilo femenino.

Figura 5. Zamia onan-reyesii. Macrosporofila con dos óvulos.

Figura 6. Zamia onan-reyesii. Corte transversal del estróbilo femenino.

Esta planta es notable por las dimensiones de su hábito y estróbilo femenino.

Etimología. El nombre del epíteto es en honor a Onán Reyes, estudiante de la Carrera de Biología de la Universidad Nacional Autónoma de Honduras, quien encontró la planta fértil después de varias excursiones al lugar tipo.

Agradecimiento. Se agradece a Sergio Chiuz por los dibujos de la planta.

\section{Literatura Citada}

Haynes, J. \& M. Bonta (2003). Cícadas de Honduras 2003. Informe final de la expedición. Miami: Montgomery Botanical Center.

Nelson Sutherland, C.H. (2005) [2007]. Dos plantas nuevas del género Zamia (Zamiaceae, Gymnospermae) en Honduras. Ceiba 46(1-2): 55-58.

Schutzman, B. (1989). A new species of Zamia from Honduras. Syst. Bot. 14(2): 214-219.

Standley, P.C. (1950). New plants from Honduras. Ceiba 1(1): 38-96.

Recibido para publicación el 3 de marzo de 2008. 